\title{
Antimicrobial Susceptibility Pattern of the Causative Bacterial Agents Among the Patients with Diabetic Foot Infection and Pneumonia in the Rajshahi Region
}

\author{
Nilufar Yasmin, ${ }^{1}$ Kh. Md. Faisal Alam, ${ }^{2}$ Md. Shah Alam, ${ }^{3}$ Rozina Aktar Zahan, ${ }^{4}$ \\ Md. Shahin Aktar Roni, ${ }^{5}$ Kaniz Fatema ${ }^{6}$
}

\begin{abstract}
Background: Infection and Diabetes often coexist, making each other the worse for it. Patients with diabetes have a greater frequency and severity of many common infections such as urinary, pulmonary, soft tissue infections. This study aims to describe the bacterial agents and determine the antimicrobial susceptibility of diabetic foot infections (DFI) and pneumonia in the Rajshahi region.

Materials and Methods: A descriptive study was performed over a period of one year in a tertiary care hospital that involved $\mathbf{1 2 0}$ patients. The aerobic bacterial agents were isolated, their antimicrobial susceptibility patterns were determined from wound swab and sputum samples.

Results: A total of 106 microorganisms were isolated among 95 culture-positive cases. The microorganism isolated were $50.94 \%(n=54) \mathrm{GN}$ (Gram-negative) and $49.06 \%(n=52)$ GP (Grampositive). GN microorganisms include Pseudomonas spp. (25.47\%), E. coli (14.15\%), Klebsiella spp. $(9.43 \%)$, and Proteus spp. (1.89\%). S. aureus (38.68\%) were predominant among GP, followed by S. pyogens $(3.77 \%)$ and Enterococcus spp. (1.89\%). About $4.72 \%$ were Coagulase Negative Staphylococcus (CoNS). S. aureus showed $95.12 \%$ sensitivity to Vancomycin and $90.24 \%$ to Imipenem. On the other hand, Pseudomonas spp. showed highest $85.19 \%$ sensitivity to Meropenem.

Conclusion: Gram-negative (GN) microorganisms were predominantly isolated from DFls and pneumonia, but $S$. aureus was the most frequently isolated organism. They showed a wide range of susceptibility towards different antimicrobials.
\end{abstract}

Keywords: Diabetic foot infection, pneumonia, antimicrobial susceptibility.

TAJ 2021; 34: No-1: 09-15

\section{Introduction}

Diabetic Foot Infection (DFI) is a major complication of diabetes, eventually leading to the development of gangrene and lower-extremity amputation, and constitutes the most frequent diabetes-related cause of hospitalization. ${ }^{12}$ The magnitude and duration of hyperglycemia are strongly associated with the severity of microvascular and neurologic complications. ${ }^{3}$ Chronic foot infections in patients with diabetes

${ }^{1}$ Lecturer, Department of Virology, Rajshahi Medical College, Rajshahi.

2 Associate Professor, Department of Microbiology, Rajshahi Medical College, Rajshahi.

3 Professor and Head, Department of Microbiology, Rajshahi Medical College, Rajshahi.

${ }^{4}$ Assistant Professor, Department of Microbiology, Rajshahi Medical College, Rajshahi.

${ }^{5}$ Lecturer, Department of Microbiology, Rajshahi Medical College, Rajshahi.

${ }^{6}$ Resident, MD (Phase-B), Department of Laboratory Medicine, BSMMU, Dhaka. 
mellitus usually complicate initially uninfected ulcerations that follow minor trauma in patients with peripheral neuropathy, chronic neuropathic ulcers or arterial vascular insufficiency and take the form of cellulitis, soft tissue necrosis or osteomyelitis. $^{4}$

The global diabetic foot infection prevalence was $6.3 \%$ and in Europe 5.1\% . In the Bangladesh Institute of Research and Rehabilitation in Diabetes, Endocrine and Metabolic Disorder (BIRDEM), they found $4 \%$ of diabetic patients were suffered from $\mathrm{DFI}^{6}$ (Islam et al., 2010).

Diabetes mellitus is often regarded as an independent risk factor for the development of lower respiratory tract infection, specially pneumonia. ${ }^{7}$ Pneumonia in itself is a serious illness associated with considerable morbidity and mortality, and any associated condition decreased body's immunity may lead to severe disease and worse outcomes. Infections due to $\mathrm{S}$. aureus, Gram-negative bacteria, and Mycobacteria occur with increased frequency in diabetic patients. DM increases the risk of community-acquired pneumonia (CAP) besides increasing the morbidity and mortality in CAP. ${ }^{7}$

These infections are difficult to treat because these patients have impaired microvascular circulation, which limits the access of phagocytic cells and poor concentration of antibiotics in the infected tissue. $^{8}$

In Bangladesh, the most frequently isolated pathogens are Gram-positive and Gram-negative aerobic organisms, including Klebsiella pneumoniae $(22.1 \%)$, Pseudomonas aeruginosa (18.2\%), Staphylococcus aureus (14.3\%), E.coli (13\%), CoNS (7.8\%) (Mohammuddunnobi et al., 2018). Bacteroides fragilis, Enterococcus faecalis, Peptostreptococcus species, Proteus vulgaris, Acinetobacter baumannii were also found. ${ }^{9}$

Many of these microorganisms develop resistance to commonly used antibiotics largely due to their indiscriminate use ${ }^{10}$ The proper management of these infections requires appropriate antibiotic selection based on culture and antimicrobial susceptibility testing, which may also help to reduce the development of multidrug resistance to avoid further complications of these already worse infections. Therefore, this study is aimed with the objective to determine the bacterial profile and antimicrobial susceptibility pattern of these infections in Rajshahi.

Methods: A cross-sectional descriptive study was conducted during the period from July 2018 till June 2019. Adult 120 diabetic patients irrespective of age and sex having DFI and pneumonia attending $\mathrm{RMCH}$ and Diabetic Association General Hospital, Rajshahi, were included in the study. Microbiological works were done in the laboratory of The Department of Microbiology, Rajshahi Medical College (RMC). Wound swabs and sputum have been collected as specimens, and data were compiled in a partially structured pretested datasheet. Culture and identification of the organisms of the specimens and antimicrobial susceptibility testing were done according to the Clinical and Laboratory Standards Institute (CLSI) guideline 2017 and World Health Organization (WHO). ${ }^{11} 12$

Results: A total of 120 specimens were collected from Diabetic Foot Infection (DFI) and pneumonia cases and cultured in different aerobic bacteriological culture media. Most of the patients were in the $41-60$ years $(75 ; 62.5 \%)$ age group, with the mean age of the study population was 56.23 years (Table 1). Overall male predominance was observed with a male-female ratio of 1.6:1. Among them, 105(87.5\%) were DFI cases, and $15(12.5 \%)$ were pneumonia cases. Total 95(79.17\%) were culture positive, and 25(20.83\%) were negative culture cases (Figure 1). The microorganism isolated were $50.94 \%(n=54) \mathrm{GN}$ (gram-negative) and 49.06\% ( $\mathrm{n}=52) \mathrm{GP}$ (grampositive) (Figure 2). GN microorganisms include Pseudomonas spp. (25.47\%), E. coli (14.15\%), Klebsiella spp. (9.43\%), and Proteus spp. (1.89\%). S. aureus $(38.68 \%)$ were predominant among GP, followed by S. pyogens $(3.77 \%)$ and Enterococcus spp. (1.89\%). About $4.72 \%$ were CoNS (Table 2). S. aureus showed $95.12 \%$ sensitivity to Vancomycin and $90.24 \%$ to Imipenem. On the other hand, Pseudomonas spp. showed the highest $85.19 \%$ sensitivity to Meropenem (Table 2). 

Table 1: Demographic data of DFI and pneumonia cases. $(N=120)$

\section{Variables}

Age (years)

Mean age

Gender

Male

Female

Presentation (Sample)

DFI (wound swab)

Pneumonia(sputum) (n \%)

(41-60, highest age group)

56.23 years

$73(60.83 \%)$

$47(39.17 \%)$

$105(87.5 \%)$

$15(12.5 \%)$

Figure 1: Culture characteristics of isolated organisms (DFI=105, pneumonia=15).

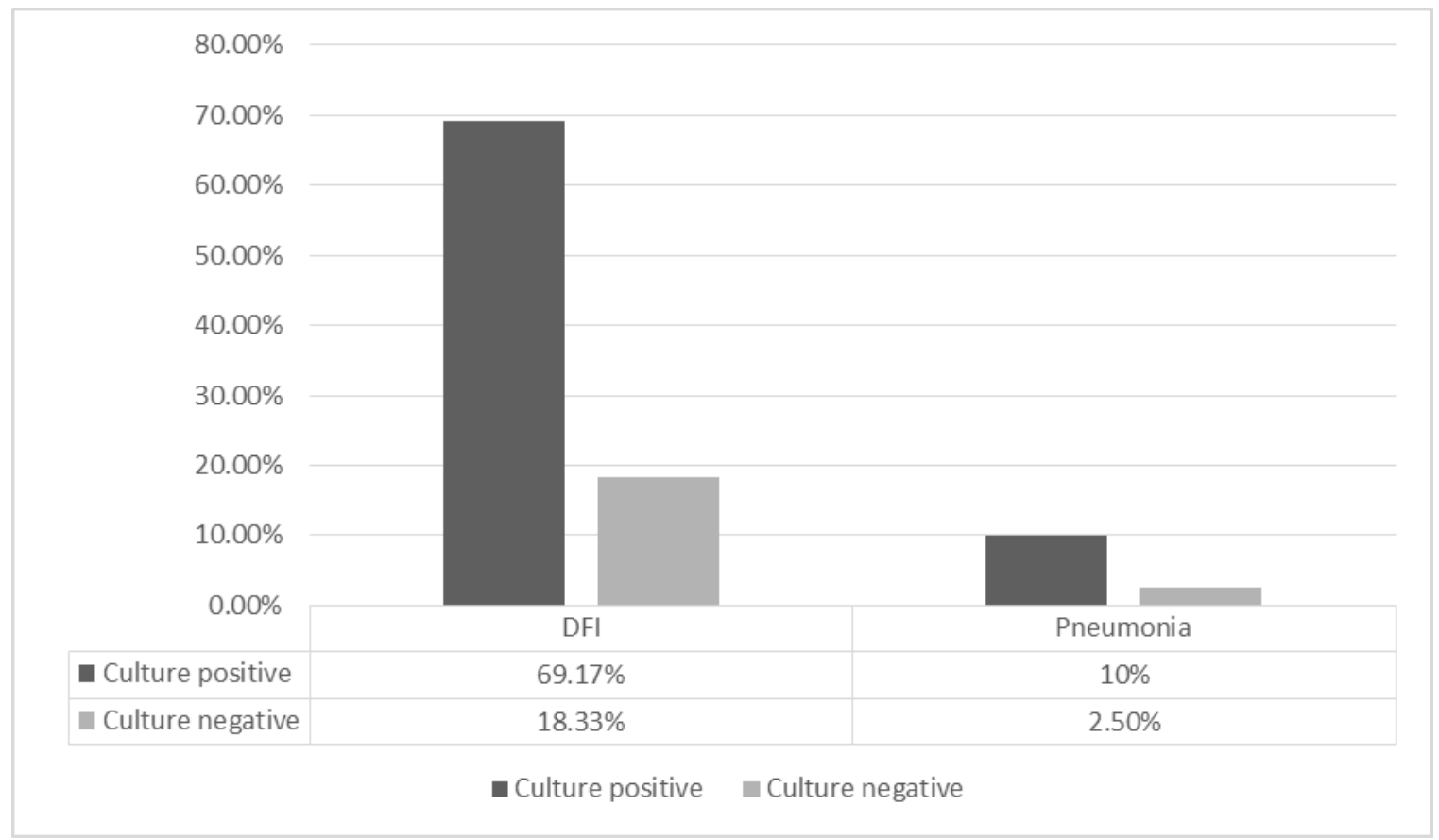


Figure 2: Distribution of isolated Gram-positive and Gram-negative bacteria from DFI and Pneumonia cases. $(\mathrm{N}=106)$

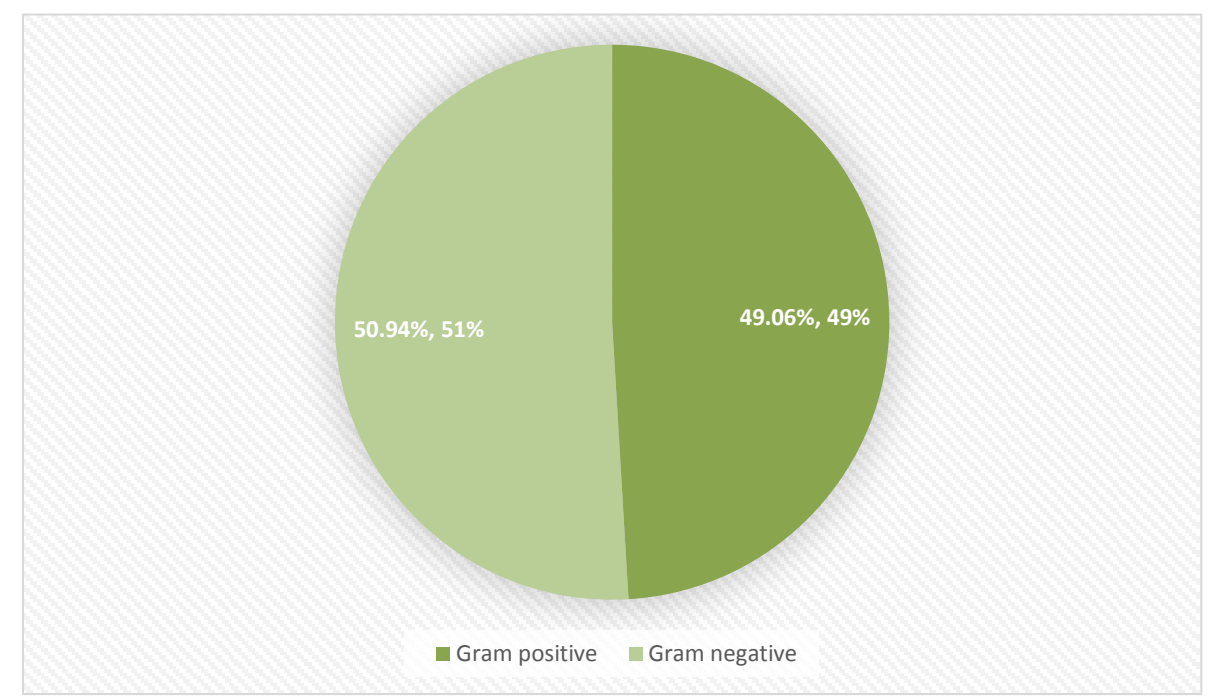

Table 2: Distribution of isolated aerobic bacteria from DFI and Pneumonia cases with their susceptibility $(\mathrm{N}=106)$

\begin{tabular}{|c|c|c|c|c|c|c|c|c|}
\hline Isolated bacteria & $\begin{array}{l}\text { S.aureus } \\
(41, \\
38.68 \%)\end{array}$ & $\begin{array}{l}S . \\
\text { pyogens } \\
(4,3.77 \%)\end{array}$ & $\begin{array}{l}\text { CoNS } \\
(5, \\
4.72 \%)\end{array}$ & $\begin{array}{l}\text { Enterococcus } \\
\text { faecalis } \\
1.89 \%)\end{array}$ & $\begin{array}{l}\text { Pseudomonas } \\
\text { aeruginosa } \\
(27,25.47 \%)\end{array}$ & $\begin{array}{l}\text { E.coli1 } \\
(5, \\
14.15 \%)\end{array}$ & $\begin{array}{l}\text { Klebsiella } \\
\text { pneumoniae } \\
(10,9.43 \%)\end{array}$ & $\begin{array}{l}\text { Proteus vulgaris } \\
(2,1.89 \%\end{array}$ \\
\hline Ceftazidime & $21.95 \%$ & $25.00 \%$ & $40.00 \%$ & $0.00 \%$ & $33.33 \%$ & $66.67 \%$ & $30.00 \%$ & $0.00 \%$ \\
\hline Azithromycin & $14.63 \%$ & $25.00 \%$ & & $0.00 \%$ & $18.52 \%$ & $26.67 \%$ & $30.00 \%$ & $0.00 \%$ \\
\hline Oxacillin & $24.39 \%$ & $25.00 \%$ & $20.00 \%$ & $0.00 \%$ & - & - & - & - \\
\hline Vancomycin & $95.12 \%$ & $100.00 \%$ & $80.00 \%$ & $100.00 \%$ & - & - & - & - \\
\hline Imipenem & $90.24 \%$ & $100.00 \%$ & $60.00 \%$ & $100.00 \%$ & $81.48 \%$ & $86.66 \%$ & $80.00 \%$ & $100.00 \%$ \\
\hline Amoxiclav & $51.22 \%$ & $50.00 \%$ & $40.00 \%$ & $50.00 \%$ & $51.85 \%$ & $60.00 \%$ & $60.00 \%$ & $50.00 \%$ \\
\hline Cefuroxime & $29.26 \%$ & $25.00 \%$ & & $0.00 \%$ & - & $60.00 \%$ & $40.00 \%$ & $0.00 \%$ \\
\hline Ceftriaxone & $21.95 \%$ & $25.00 \%$ & $20.00 \%$ & $0.00 \%$ & $14.81 \%$ & $46.67 \%$ & $30.00 \%$ & $0.00 \%$ \\
\hline Ciprofloxacin & $53.66 \%$ & - & $40.00 \%$ & $50.00 \%$ & $33.33 \%$ & $53.33 \%$ & $70.00 \%$ & $50.00 \%$ \\
\hline Gentamycin & $78.05 \%$ & $75.00 \%$ & $60.00 \%$ & $50.00 \%$ & $51.85 \%$ & $80.00 \%$ & $40.00 \%$ & $50.00 \%$ \\
\hline Amikacin & $43.90 \%$ & $50.00 \%$ & $40.00 \%$ & $100.00 \%$ & - & $53.33 \%$ & $60.00 \%$ & $100.00 \%$ \\
\hline $\begin{array}{l}\text { Piperacillin/Tazob } \\
\text { actam }\end{array}$ & - & - & & - & $77.78 \%$ & - & - & - \\
\hline Meropenem & - & - & $60.00 \%$ & - & $85.19 \%$ & $80.00 \%$ & $80.00 \%$ & $100.00 \%$ \\
\hline Polymyxin & - & - & & - & $92.59 \%$ & - & - & - \\
\hline Colistin & - & - & & - & $92.59 \%$ & - & - & - \\
\hline
\end{tabular}




\section{Discussion}

This study included 120 patients with Diabetes mellitus presenting with wound infection and pneumonia $(105+15=120)$ (Table 1$)$. The highest age group was (41-60) years $(62.50 \%)$ with a mean age of 56.23 years (Table 1), which was similar to an Indian study. ${ }^{13}$ As age increases, the chance of getting foot infections and pneumonia also increases.

Male $(60.83 \%)$ were predominant subjects in both DFI and Pneumonia cases (Table 1). India and Bangladesh also reported alike with present study. ${ }^{14,15}$

In this study, most of the specimens from DFI $(69.17 \%, \mathrm{n}=83)$ and pneumonia $(10 \%, \mathrm{n}=12)$ cases were culture-positive (Figure 1). Out of 105 DFI cases, $83(79.05 \%)$ were culture positive. It is similar to the studies from Indonesia. ${ }^{16}$ On the other hand, some studies showed more than $90 \%$ culture-positive cases of DFI, which were dissimilar with this study. ${ }^{17}$

In the present study, among 15 pneumonia cases, $12(80 \%)$ were culture positive (Figure 1). In Bangladesh, $76 \%$ culture-positive pneumonia cases were found, which was similar to the present study. ${ }^{18}$ The culture-negative cases might be due to patients already receiving antibiotics prior to sample collection or due to infection caused by anaerobic organisms or fungus.

In DFI cases, the isolates were predominantly gram-negative $(51.06 \%)$, and in pneumonia cases, the isolates were $50 \%$ gram-positive and $50 \%$ gram-negative (Figure 2).

Overall, 106 isolates were found from 95 culturepositive cases; among them, 54(50.94\%) were gram-negative, and 52(49.06\%) were grampositive. Similar findings were found in Korea. ${ }^{17}$ In their study, they found near equal distribution of gram-positive and gram-negative growth, like the present study. There are some other studies that showed the opposite picture of the present study. They found the majority of growth as gramnegative. ${ }^{16}$ This might be due to the variation of organisms from region to region.
In this study several aerobic organisms were isolated (Table 2) from DFI and pneumonia cases such as $S$. aureus $(41,38.38 \%)$, Pseudomonas aeruginosa (27, 25.47\%), E.coli (15, 14.15\%), Klebsiella pneumoniae (10, 9.43\%), CoNS (5, 4.72\%), Streptococcus pyogens (4, 3.77\%), Enterococcus faecalis $(2,1.89 \%)$ and Proteus vulgaris $(2,1.89 \%)$. This study was in agreement with other studies conducted in Korea, India, and Bangladesh. ${ }^{17,14,9}$

The variation in organisms might be multifactorial, such as geographical location, personal hygiene, presence of other systemic diseases, and prolonged stay in hospital.

The pattern of antimicrobial resistance is important for epidemiological and clinical purposes. For the rational use of antibiotics, it is important to choose appropriate antibiotics in this era of multidrug-resistant (MDR) organisms.

The present study shows antimicrobial susceptibility pattern of $S$. aureus (Table 2) that were the predominant organism, showed the highest sensitivity to Vancomycin (95.12\%) followed by Imipenem (90.24\%) and Gentamycin $(78.05 \%)$. This study was in conformity with the reports of some Pakistani and Bangladeshi studies. ${ }^{19,20}$

Pseudomonas aeruginosa in the study showed (Table 2) the highest sensitivity to Meropenem $85.19 \%$, followed by Imipenem $81.48 \%$ and Piperacillin/Tazobactam $77.78 \%$. These findings were nearly comparable with other studies. ${ }^{21}$ In the present study, we found $92.59 \%$ sensitivity for Colistin and Polymyxin B. Some studies found $100 \%$ sensitivity towards these drugs, which were near similar to this study.22

In our study, we found E.coli, which showed 86.66 $\%, 80.00 \%$, and $80 \%$ sensitivity to Imipenem, Meropenem, and Gentamycin, respectively (Table 2). Near similar report was found in the study conducted in India and Pakistan. ${ }^{21,19}$

Increased resistance to Ceftazidime $(60 \%)$ was noted among the Klebsiella pneumoniae isolated in the study group. In India, 50\% resistance to Ceftazidime was found. ${ }^{23}$ Overall, Imipenem, 
Meropenem, and Vancomycin were found to be the most effective drugs for these patients so far.

\section{Conclusion:}

DFI and pneumonia s are common among diabetic patients in this region. Most of the patients are above 40 years of age with male predominance. The majority of the specimen were culture positive. Though gram-negative bacteria are the dominating bacteria, $S$. aureus is the most prevalent one. Vancomycin and Imipenem are the drugs of choice for most gram-positive bacteria, and Meropenem and Imipenem are found to be effective against gram-negative bacteria.

\section{References}

1. Raja NS. Microbiology of diabetic foot infections in a teaching hospital in Malaysia: a retrospective study of 194 cases. J Microbiol Immunol Infect. 2007; 40: 39-44.

2. Spichler A, Harwitz BL, Armstrong DG, Lipsky BA. Microbiology of diabetic foot infections: from Louis Pasteur to crime scene investigation. BMC Medicine. 2015; 13(1):2. https://doi.org/ 10.1186/ s12916-014-0232-0

3. Kornum JB, Thomsen RW, Riis A, Larvang $\mathrm{HH}$, Schonheyder HC, Soreman HT. Type 2 diabetes and pneumonia Outcomes, a population-based cohort study. Diabetes care. 2007; 30(9): 2251-7.

4. Pasternack MS and Swast ZMN. Cellulitis, necrotizing fasciitis and subcutaneous tissue infection. Chapter 95.In: Mandell, Doughs and Bennett's Principles and Practice of Infectious Diseases, 8th ed. Bennett JE, Dolin R, Blases MJ, Editors, Elsevier Saunders. 2015; 1:1194-1215.

5. Penzi Z, Jing L, Yali J, Sunyiayan T, Dalong $Z$ and Yan B. Global epidemiology of diabetic foot ulceration; a systemic review and meta-analysis. ANNALS of MEDICINE. 2017; 49(2):106-116.

6. Khwaja NU. Diabetes Mellitus Specific Infections. BIRDEM Med J.2017; 7(1): 1-5

7. Sameer $\mathrm{Y}$, Pramod D, Tukaram $\mathrm{J}$ and Moulick. A study of clinical profile of community acquired pneumonia in diabetes mellitus. International Journal of Recent Trends in Science and Technology September. 2016; 20(2): 163-168.

8. Seyed MA, Azar DK, Abdulah S, Ahmad D, Effat AM. Bacteriological study of diabetic foot ulcer. Pakistan Journal of Medical Sciences Online. 2007; 23(5): 681-4.
9. Mousumi K. Characterization of Microbial Agents in Diabetic Foot Infections and its Correlation with Chronic Subclinical Inflammation.2014:55-56.

10. Pitte D, Wyss B, Herter Clevel C, Kursteines K, Vauches $\mathrm{J}$ and Lew P P. Outcome of diabetic foot infections treated conservatively, a retrospective cohort study with long term follow up. Arch Inter Med. 1998; 159:851-6.

11. World Health Organization (WHO), Antimicrobial resistance: global report on surveillance 2014. Geneva, Switzerland: WHO; 2014.

12. CLSI. Performance Standards for Antimicrobial Susceptibility Testing .27th ed. CLSI supplement M100.Wayne, P.A.: Clinical and Laboratory Standards Institute, 2017.

13. Vasanthan $\mathrm{K}$, Vengadakrishnan $\mathrm{K}$ and Surendran P. Clinical Profile of Diabetic Foot Infections. Int J Sci Stud.2018; 6(1):24-27.

14. Sivaraman U, Shailesh K, Noyal M J, Joshy M E, Kandhakumari, Sreenivasan S, Sruthi R and Selvaraj S. Microbiological study of diabetic foot infections. Indian Journal of Medical Specialities. $2011 ; 2(1): 12-17$.

15. Ahmed JU, Hossain MD, Rahim MA, Afroz F and Musa AKM. Bacterial Etiology and Antibiotic Sensitivity Pattern of Community Acquired Pneumonia in Diabetic Patients: Experience in a Tertiary Care Hospital in Bangladesh .BIRDEM Med J. 2017; 7(2):101-10.

16. Pemayun TGD and Naibaho RM. Clinical profile and outcome of diabetic foot ulcer, a view from tertiary care hospital in Semarang, Indonesia. Diabetic Foot and Ankle. 2017; 8(1):1-10.

17. Son ST, Han SK, Lee TY, Sik N and Dhong ES. The Microbiology of Diabetic Foot infections in Korea. J Wound Management Res.2017; 13(1): 812.https://doi.org/10.22467/jwmr.2017.00108.

18. Saibal MAA, Rahman SHZ, Nishat L, Sikder NH, Begum SA, Islam MJ and Uddin KN. Community acquired pneumonia in diabetic and non-diabetic hospitalized patients: presentation, causative pathogens and outcome, 2012. Bangladesh Med Res Counc Bull. 2012;38: 98-103

19. Amjad SS, Zafar J and Nadia S. Bacteriology of Diabetic Foot In Tertiary Care Hospital; Frequency, Antibiotic Susceptibility and Risk Factors. J Ayub Med Coll Abbottabad. 2017; 29 (2):234-40.

20. Shameem A, Haque SMZ, Mushfequr R and Hafez MA. Study of bacterial infection and antimicrobial sensitivity pattern in diabetic foot lesion. Bangladesh J Med Microbiol. 2012;6(2): 20-23 
21. Katherine J, George AT, Divya MB and Ameena KK. Diabetic Foot Infections: Characterization and Antibiotic Resistance Pattern of Aerobic Bacterial Isolates in a Tertiary Care Hospital of North Kerala. Int. J. Curr. Microbiol. App. Sci. 2017; 6(9):34933499. doi: https://doi.org/ 10.20546/ ijcmas. 2017. 609.429

22. Ahmed JU, Hossain MD, Rahim MA, Afroz F and Musa AKM. Bacterial Etiology and Antibiotic
Sensitivity Pattern of Community Acquired Pneumonia in Diabetic Patients: Experience in a Tertiary Care Hospital in Bangladesh .BIRDEM Med J. 2017;7(2):101-10

23. Banashankari GS, Rudresh $\mathrm{HK}$ and Harsha $\mathrm{AH}$ Prevalence of Gram Negative Bacteria in Diabetic Foot-A Clinico-Microbiological Study. Al Ameen J Med Sci. 2012; 5(3): 224-232.

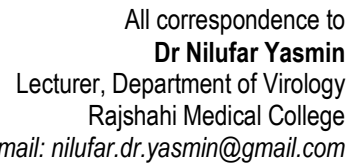

